\title{
Quality of care received for family planning from community pharmacists and patent and proprietary medicine vendors in Lagos and Kaduna, Nigeria: The IntegratE project
}

Population Council

Follow this and additional works at: https://knowledgecommons.popcouncil.org/departments_sbsr-rh

Part of the Health Services Research Commons

How does access to this work benefit you? Let us know!

\section{Recommended Citation}

"Quality of care received for family planning from community pharmacists and patent and proprietary medicine vendors in Lagos and Kaduna, Nigeria: The IntegratE project," IntegratE Project brief. Abuja:

Population Council, 2020. 


\section{BACKGROUND}

In Nigeria, Community Pharmacists (CPs) and Patent and Proprietary Medicine Vendors (PPMVs) are the first point of care for many communities. Although CPs and PPMVs are not formally recognized as FP service providers, $22 \%$ of modern contraceptive users' report receiving their last method from a PPMV and $12 \%$ from a private pharmacy [2]. PPMVs are especially popular for family planning (FP) due to their widespread availability, consistent drug stocks, extended hours, personable interactions, and no separate fees for consultations [3, 4]. As the Federal Ministry of Health $(\mathrm{FMoH})$ explores expanding its task sharing policy to include CPs and PPMVs, evidence is needed on an effective regulatory system to support PPMVs and CPs to provide high quality FP services.

\section{THE INTEGRATE PROJECT}

The IntegratE Project is a 4-year initiative (2017-2021) funded by the Bill \& Melinda Gates Foundation and MSD for Mothers ${ }^{1}$ that seeks to increase access to contraceptive methods by involving the private sector (CPs and PPMVs) in FP service delivery in Lagos and Kaduna States. IntegratE is implemented by a consortium of partners, Marie Stopes International, Planned Parenthood Federation of Nigeria, Population Council, PharmAccess, and led by the Society for Family Health. The project seeks to establish a regulatory system with the Pharmacists Council of Nigeria (PCN) to ensure that CPs and PPMVs provide quality FP services, comply with FP regulations and report service statistics to the Health Information Management System (HMIS). To achieve this, the IntegratE Project in collaboration

11 This programme is co-funded by, developed and is being implemented in collaboration with MSD for Mothers, MSD's $\$ 500$ million initiative to help create a world where no woman dies giving life. MSD for Mothers is an initiative of Merck \& Co., Inc., Kenilworth, NJ, U.S.A with PCN and the $\mathrm{FMoH}$, is implementing three main activities: (1) a pilot 3-tiered accreditation system for PPMVs based on their healthcare qualifications; (2) a pilot hub-and-spoke supervisory model to ensure standard drug stocking practices; and (3) building the capacity of CPs and PPMVs to provide expanded FP services and report service statistics to the HMIS. Under the pilot accreditation system, PPMVs are provided with a standardized FP training and offer certain FP services based on their tier (Table 1). CPs function outside of the pilot accreditation system but would receive the same training and provide the same services as Tier 2 PPMVs. The IntegratE Project is simultaneously raising awareness about the FP services CPs and PPMVs provide. This brief focuses on quality of care received by women voluntarily seeking FP services from CPs and PPMVs. Additional information on IntegratE Project can be found on www.integrateeproject.org.ng.

\begin{tabular}{|c|c|c|}
\hline $\begin{array}{l}\text { Provider } \\
\text { type }\end{array}$ & Description & Training received \\
\hline $\begin{array}{l}\text { Tier } 1 \\
\text { PPMVs }\end{array}$ & $\begin{array}{l}\text { PPMVs without } \\
\text { healthcare } \\
\text { qualifications }\end{array}$ & $\begin{array}{l}\text { - FP counseling and referral } \\
\text { - Refill of oral contraceptives }\end{array}$ \\
\hline $\begin{array}{l}\text { Tier } 2 \\
\text { PPMVs }\end{array}$ & $\begin{array}{l}\text { PPMVs with } \\
\text { healthcare } \\
\text { qualifications }\end{array}$ & $\begin{array}{l}\text { - FP counseling and referral } \\
\text { - Injectable administration } \\
\text { - Implant insertion and removal }\end{array}$ \\
\hline $\begin{array}{l}\text { Tier } 3 \\
\text { PPMVs }\end{array}$ & $\begin{array}{l}\text { PPMVs who are } \\
\text { also pharmacy } \\
\text { technicians }\end{array}$ & $\begin{array}{l}\text { - FP counseling and referral } \\
\text { - Injectable administration } \\
\text { - Implant insertion and removal }\end{array}$ \\
\hline CPs & $\begin{array}{l}\text { Outside of } \\
\text { accreditation } \\
\text { system }\end{array}$ & $\begin{array}{l}\text { - FP counseling and referral } \\
\text { - Injectable administration } \\
\text { - Implant insertion and removal }\end{array}$ \\
\hline
\end{tabular}

THE MAJORITY OF WOMEN (98\%) FELT

THAT THEY WERE ALLOWED TO ASK QUESTIONS DURING THEIR FP COUNSELING SESSIONS WITH CPS AND PPMVS 


\section{QUALITY OF CARE RECEIVED BY CLIENTS SEEKING FAMILY PLANNING SERVICES FROM CPS AND PPMVS}

The IntegratE project is conducting a mixed-methods study to assess the effect of a series of interventions on CPs' and PPMVs' capacity to provide high quality FP services. Between June and November of 2019, women were interviewed after receiving FP services from trained CPs and PPMVs. 598 women who received FP services from CPs in Kaduna and Lagos states were contacted within a week of receiving services by a data collector by phone about the services that they received. Additional women will be enrolled in the study in 2020.

\section{RESULTS}

\section{Respondent characteristics}

Just over half of women interviewed were between the ages of 25 and 34 (54\%) in Kaduna, and 35 or older (53\%) in Lagos. Nearly all women in both states were married or in-union (95\% in Kaduna and 93\% in Lagos) and had at least one child (96\% in Kaduna and $97 \%$ in Lagos). Most had completed secondary school or higher (58\% in Kaduna and $79 \%$ in Lagos).

\section{WOMEN REPORTED RECEIVING A RANGE OF INFORMATION ABOUT METHOD SELECTION, FROM A HIGH OF $96 \%$ WHO WERE TOLD ABOUT OTHER FP METHODS TO A LOW OF $58 \%$ IN LAGOS WHO WERE TOLD ABOUT WHICH METHODS PROTECT AGAINST STIS/HIV.}

\section{Quality of care received}

The measures of quality of care assessed in this study are broken down into four key domains [6]: 1) respectful care, 2) method selection, 3) effective use of selected method, and 4) continuity of contraceptive use and care. Figure 1 presents the proportions of women who reported high quality by domain $\left(n=497^{2}\right)$. Respectful care includes interpersonal interactions between the provider and woman and assesses aspects of privacy and confidentiality. In both states, women reported high

\footnotetext{
2101 women were inadvertently skipped from the quality of care questions
}

\begin{tabular}{|c|c|c|c|}
\hline & $\begin{array}{l}\text { Kaduna } \\
(n=298)\end{array}$ & $\begin{array}{c}\text { Lagos } \\
(n=300)\end{array}$ & $\begin{array}{c}\text { Total } \\
(n=598)\end{array}$ \\
\hline \multicolumn{4}{|l|}{ Age } \\
\hline $16-24$ & 22.2 & 5.0 & 13.6 \\
\hline $25-34$ & 54.0 & 42.3 & 48.2 \\
\hline $35-53$ & 23.8 & 52.7 & 38.3 \\
\hline \multicolumn{4}{|l|}{ Marital Status* } \\
\hline Single & 4.4 & 5.3 & 4.9 \\
\hline Married/In-union & 94.6 & 93.3 & 94.0 \\
\hline Widowed/divorced & 0.7 & 1.3 & 1.0 \\
\hline \multicolumn{4}{|l|}{ Number of living children* } \\
\hline None & 4.0 & 3.3 & 3.7 \\
\hline One & 10.4 & 9.7 & 10.0 \\
\hline Two & 23.2 & 15.0 & 19.1 \\
\hline Three & 20.8 & 35.0 & 27.9 \\
\hline Four or more & 41.3 & 37.0 & 39.1 \\
\hline \multicolumn{4}{|c|}{ Highest level of education achieved* } \\
\hline No formal education & 12.8 & 3.3 & 8.0 \\
\hline Primary & 18.8 & 14.0 & 16.4 \\
\hline Secondary & 49.0 & 41.7 & 45.3 \\
\hline $2+$ years post-secondary & 18.5 & 37.7 & 28.1 \\
\hline
\end{tabular}

quality of care for 5 of the 6 items in the respectful care domain. Nearly all women felt that they were treated well by the provider (99\% in Kaduna and 100\% in Lagos) and that their information would be kept confidential (99\% in Kaduna and 96\% in Lagos). Fewer in each state felt that audio privacy was ensured during the visit ( $88 \%$ in Kaduna and $91 \%$ Lagos), and that visual privacy was ensured (66\% in Kaduna and $74 \%$ Lagos).

Method selection focuses on information sought by providers to facilitate women's choice of method. At least $90 \%$ of women in both states reported discussion of 4 of the 7 items related to method selection. For example, most women reported that the provider told them about other FP methods (96\% in each state) and asked about their preferred method (95\% in Kaduna and $96 \%$ in Lagos). Fewer women reported aspects of quality for the other 3 items. For example, providers were trained not to promote any one method. Interviews showed that in Lagos, $87 \%$ of women reported that no method was strongly promoted, and $70 \%$ reported this in Kaduna. Sixty-eight percent of women in Kaduna and $58 \%$ in Lagos reported that the provider gave them information about FP methods that protect against STIs. 
Figure 1: Percentage of women reporting quality of care received from CPs and PPMVs by domain and State $n=497$

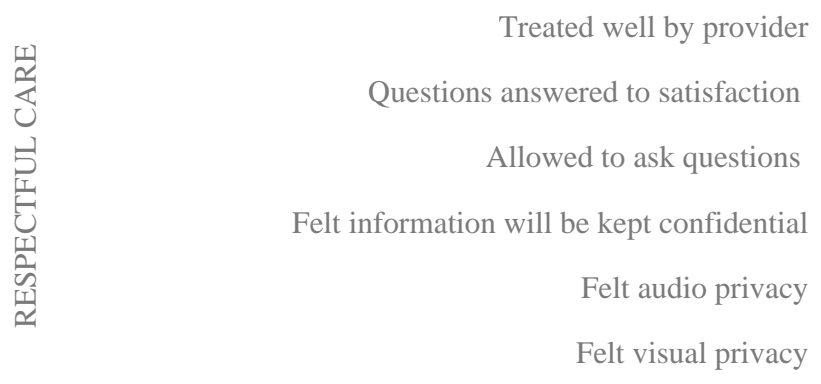

Told about other methods

Asked about preferred FP method

Asked about previous FP experience

Asked about desire for another child

Asked about preferred timing of next child

Received information without any method promoted

Received information on methods that protect against STIs

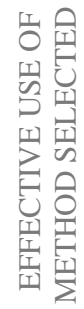

Told how chosen method works

Told how to use chosen method

Told about warning signs associated with method

Told about possible side effects of chosen method

Told how to manage side effects/problems

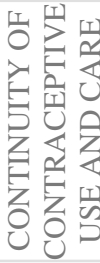

Told about timing of next visit

Given appointment card for follow up visit

Told about other sources of FP supply

Told about the possibility of switching method

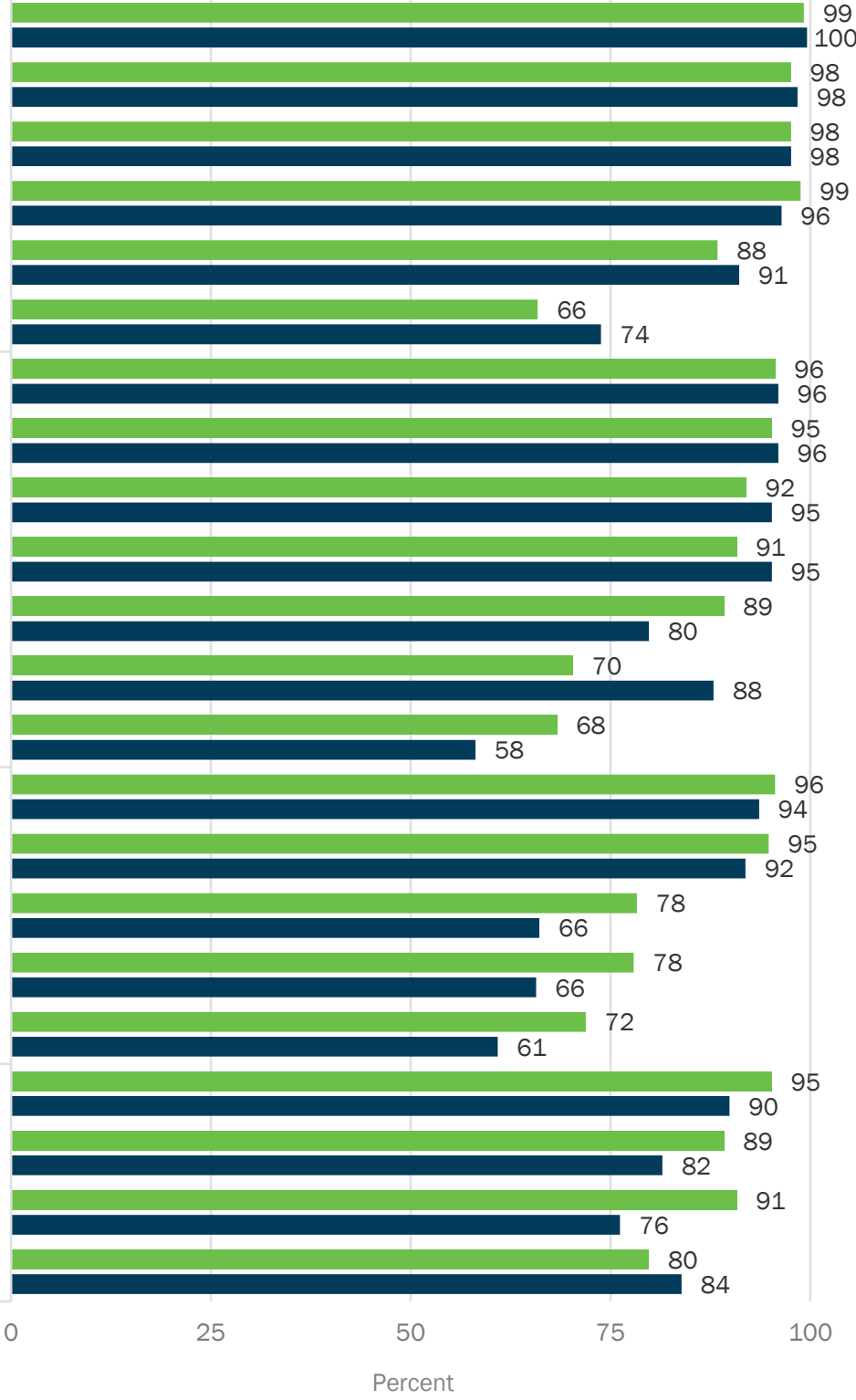

Percent

Kaduna $n=249$ Lagos $n=248$

Effective use of the selected method includes information about how to safely and effectively use the method. Most women reported that the provider told them how their chosen method works (96\% in Kaduna and $94 \%$ in Lagos) and how to use it (95\% in Kaduna and $92 \%$ in Lagos). Fewer reported that the provider told them about the possible side effects of the chosen method (78\% in Kaduna and 66\% in Lagos) and how to manage those side effects (72\% in Kaduna and $61 \%$ in Lagos).
FOR THEIR CHOSEN METHOD, 78\% OF

WOMEN IN KADUNA AND $67 \%$ IN LAGOS WERE TOLD ABOUT POSSIBLE SIDE EFFECTS AND $72 \%$ OF WOMEN IN KADUNA AND 61\% OF WOMEN IN LAGOS WERE TOLD HOW TO MANAGE THEM. 
Continuity of contraceptive use and care includes information about follow-up appointments and the ability to switch to other methods. Most women were told about the timing of their next FP visit (95\% in Kaduna and $90 \%$ in Lagos). Many were told that they could switch to another method if the method selected wasn't suitable (89\% in Kaduna and $82 \%$ in Lagos) and about other sources of FP supply (84\% in Kaduna and $80 \%$ in Lagos).

\section{MORE THAN THREE-QUARTERS OF WOMEN REPORTED RECEIVING EACH ITEM IN THE CONTINUITY OF CONTRACEPTIVE USE AND CARE DOMAIN.}

\section{Level of quality of care received by women seeking family planning from CPs and PPMVs}

A composite scale combining the 22-items into low, medium and high quality of care received was calculated based on methods used in previous studies [7]. Forty percent of women were categorized as receiving high quality of care, $36 \%$ as medium quality of care, and $24 \%$ as low quality of care.
In addition, $97 \%$ of women said they would return to the same CP or PPMV for FP in the future, and $98 \%$ said they would recommend the same provider to a friend ${ }^{3}$.

\section{CONCLUSION}

Results to date suggest that just over three-quarters of women seeking FP services from IntegratE-trained CPs and PPMVs received medium to high quality of care. These findings are promising for the ability of CPs and PPMVs to provide high quality care to clients seeking FP services in Nigeria. The IntegratE Project plans to use these results to help inform future FP counseling trainings and mentorship support to CPs and PPMVs to ensure that women seeking services from CPs and PPMCs continue to receive high quality services. Through additional client exit interviews planned for Year 3 of the project, changes in quality of care received from trained CPs and PPMVs will be assessed.

References

1. Nigerian Pharmacy Law, Chapter 92, 1964. Federal Ministry of Health, Lagos, Nigeria.

2. National Population Commission (NPC) [Nigeria] and ICF. 2019. Nigeria Demographic and Health Survey 2018. Abuja, Nigeria, and Rockville, Maryland, USA: NPC and ICF.

3. Brugha R, Zwi A (2002) "Improving the quality of private sector delivering of public health services: challenges and strategies." Health Policy Plan, 13:103-120.

4. Adetunji JA (1991) "Response of parents to five killer diseases among children in a Yoruba community, Nigeria." Social Science Medicine 32:1379-1387.

5. Ishaku, Salisu, Kayode Afolabi, Sara Chace Dwyer, Faizah Okunade, Chiamaka Uzomba, Adedamola Adebayo, Elizabeth Tobey, and Aparna Jain. 2018. "Examining and Strengthening the Role of Patent and Proprietary Medicine Vendors in the Provision of Injectable Contraception in Nigeria," Research Report. Washington, DC: Population Council, The Evidence Project.

6. Jain Anurdh K., John Townsend, and Saumya RamaRao. 2018. Proposed metrics to measure quality: An overview. Working Paper no. 3, prepared for the Measuring and Monitoring Quality of Care Project. New York: Population Council.

7. Jain Aparna, Kumudha Aruldas, Arupendra Mozumdar, Elizabeth Tobey, and Rajib Acharya. 2019. "Validation of Two Quality of Care Measures: Results from a Longitudinal Study of reversible Contraceptive Users in India" Studies in Family Planning. 50 (2).

\footnotetext{
$3(n=563) 35$ women were inadvertently skipped from these questions
} 